\title{
Assessment of MERIS ocean color data products for European seas
}

\author{
G. Zibordi, F. Mélin, J.-F. Berthon, and E. Canuti \\ European Commission, Joint Research Centre, Institute for Environment and Sustainability, Ispra, Italy \\ Correspondence to: G. Zibordi (giuseppe.zibordi@jrc.ec.europa.eu)
}

Received: 18 December 2012 - Published in Ocean Sci. Discuss.: 29 January 2013

Revised: 13 April 2013 - Accepted: 27 April 2013 - Published: 27 May 2013

\begin{abstract}
The accuracy of marine data products from the Medium Resolution Imaging Spectrometer (MERIS) operated on board the Envisat platform is investigated with the aid of in situ geographically distributed measurements from different European seas. The assessment focuses on standard products from the 2012 data update commonly identified as 3rd Reprocessing. Results indicate atmospherically corrected data affected by a negative bias of several tens percent at the $413 \mathrm{~nm}$ center wavelength, significantly decreasing to a few percent at $560 \mathrm{~nm}$ and increasing again at $665 \mathrm{~nm}$. Such an underestimate at the blue center wavelengths leads to an average overestimate of the algal-1 MERIS pigment index largely exceeding $100 \%$ for the considered European seas. A comparable overestimate is also observed for the algal-2 pigment index independently determined from topof-atmosphere radiance through the application of neural networks.
\end{abstract}

\section{Introduction}

From 2002 till 2012, the Envisat mission of the European Space Agency (ESA) produced data of the Earth's atmosphere, cryosphere, land and oceans to advance the understanding, modeling, and prediction of environmental and climate changes. The Envisat payload included the Medium Resolution Imaging Spectrometer (MERIS) designed for ocean color, vegetation and cloud observations (Louet, 2001). The fundamental satellite ocean color data product is the radiance emerging from the sea determined from the top-of-atmosphere signal. This radiometric quantity carries information on seawater optically significant constituents (i.e. phytoplankton, colored dissolved organic matter, non-pigmented particles) and specifically allows for the determination of pigments (e.g. chlorophyll $a$ ) concentration.
The latter derived quantity is conveniently used as a proxy for phytoplankton biomass applied for water quality monitoring (Brando and Dekker, 2003; Hu et al., 2004; Attila et al., 2013) and for the quantification of the impact of climate change on marine ecosystems (Hays et al., 2005, HoeghGuldberg and Bruno, 2010). Within such a context, highly accurate data products are essential to detect changes and quantify trends (Ohring et al., 2005). Such a requirement, however, imposes a continuous effort to assess uncertainties and biases affecting remote sensing data products.

This work presents and discusses uncertainties and biases of MERIS ocean color products for European seas determined from the 2012 data processing commonly identified as 3rd Reprocessing. The analysis is primarily performed using in situ measurements. However, data products from different satellite ocean color missions are also considered for appraisal.

\section{Data and methods}

The primary satellite ocean color product evaluated in this study is the spectral normalized water leaving radiance $L_{\mathrm{WN}}$ (Morel et al., 2002) determined from top-of-atmosphere radiometric data through minimization of atmospheric perturbations (i.e. the atmospheric correction process). Derived standard products like pigment concentrations and absorption coefficients of optically significant seawater components are also evaluated. The in situ reference data utilized for the assessment are from the ocean color component of the Aerosol Robotic Network (AERONET-OC, see Zibordi et al., 2009a), the Bio-Optical mapping of Marine Properties (BiOMaP, see Zibordi et al., 2011) and the Coastal Atmosphere and Sea Time Series (CoASTS, see Zibordi et al., 2002) measurement programs. The study focuses on European seas and embraces very different water types which, 
according to a basic classification scheme, vary from the socalled case-1 waters with bio-optical properties mostly explained by phytoplankton and its by-products, to case- 2 waters characterized by independent contributions from optically significant constituents.

\subsection{Satellite data products}

Major differences between the MEGS-8 processor applied for the 3rd Reprocessing with respect to the previous version, MEGS-7, comprise (see Bourg et al., 2011): (i) the use of vicarious calibration relying on in situ data to remove a significant positive bias affecting data determined from the application of the classical case-1 water atmospheric correction (see Antoine and Morel, 1999); (ii) an extensive revision of the so-called bright pixel atmospheric correction (BPAC, see Moore et al., 1999), aiming at improving the performance of the case- 1 atmospheric correction over turbid waters; and (iii) the addition of neural networks allowing for a dedicated case- 2 water atmospheric correction and data products generation. Because of this, MERIS products from the 3rd Reprocessing are conveniently separated into fully independent case- 1 and case- 2 water data products. It is, however, underlined that the validity of $L_{\mathrm{WN}}$ from the case- 1 water data processing extends to case- 2 sediment dominated waters through the application of BPAC. Additionally, the neural network processor designated for the generation of case-2 water products is also expected to perform in case- 1 waters. Ultimately, the domain of applicability of each standard data product is granted by specific confidence flags: data products are definitely retained for successive application when the related confidence flags are valid, as detailed in Sect. 2.3.

The so-called spectral normalized water-leaving reflectance $R_{\mathrm{rs}}$ is the output of the case- 1 water data processing. For the purpose of this work, $R_{\mathrm{rs}}$ (dimensionless) is converted into $L_{\mathrm{WN}}$ in units of $\mathrm{mW} \mathrm{cm}{ }^{-2} \mu \mathrm{m}^{-1} \mathrm{sr}^{-1}$ through

$L_{\mathrm{WN}}=R_{\mathrm{rs}} \frac{E_{0}}{\pi} C_{\mathrm{f} / \mathrm{Q}}$

where $E_{0}$ in units of $\mathrm{mW} \mathrm{cm}{ }^{-2} \mu \mathrm{m}^{-1}$ is the mean extraterrestrial solar irradiance from Thuillier et al. (2003), and the term $C_{\mathrm{f} / \mathrm{Q}}$ (dimensionless) is introduced to remove the offnadir viewing angle dependence and the anisotropy effects of the in-water light field (Morel et al., 2002).

Derived MERIS case-1 data product is the so-called algal1 pigment index, indicating the total chlorophyll $a$ concentration resulting from the sum of monovinyl chlorophyll $a$, divinyl chlorophyll $a$, chlorophyllide and phaeophytin $a$. Specifically, algal-1 in units of $\mu \mathrm{g} \mathrm{L}^{-1}$ is determined through a polynomial regression relying on multiple band ratios of $R_{\mathrm{rs}}$ (Morel et al., 2007) corrected for the effects of off-nadir viewing angle and in-water light anisotropy (Bourg et al., 2011). Additional products resulting from the case- 1 water atmospheric correction are the aerosol optical thickness at $869 \mathrm{~nm}, \tau_{\mathrm{a}}(869)$ (dimensionless), and the Ångström expo- nent $\alpha$ expressing the spectral dependence of $\tau_{\mathrm{a}}$. These latter products, which support diagnostics of the atmospheric correction process, also have major relevance for climate investigations (McClain, 2009).

MERIS Case- 2 data products include the algal-2 pigment index in units of $\mu \mathrm{gL}^{-1}$, the total suspended matter concentration TSM in units of $\mathrm{mgL}^{-1}$, and the combined absorption coefficients of colored dissolved organic matter and non-pigmented particles at $443 \mathrm{~nm}, a_{\mathrm{dg}}(443)$ in units of $\mathrm{m}^{-1}$. The algal-2 pigment index is determined as algal-2 $=21.0$ $a_{\mathrm{ph}}(443)^{1.04}$, where the power-law coefficients were derived from measurements performed in the German Bight and Norwegian waters (Antoine et al., 2012) and $a_{\mathrm{ph}}(443)$ is the absorption coefficient of pigmented particulate matter at $443 \mathrm{~nm}$ (an output of the case- 2 water neural network). TSM is determined as TSM $=1.73 \times b_{\mathrm{p}}(443)$, where the multiplying coefficient was derived from measurements performed in the North Sea (Antoine et al., 2012) and $b_{\mathrm{p}}(443)$ is the scattering coefficient of particles at $443 \mathrm{~nm}$ in units of $\mathrm{m}^{-1}$ (an additional output of the case- 2 water neural network).

It is anticipated that in view of comprehensively discussing results from the comparison of MERIS and in situ $L_{\mathrm{WN}}$ data, equivalent analyses are also proposed for data from different satellite ocean color sensors. These are the Sea-viewing Wide Field-of-view Sensor (SeaWiFS) and the Moderate Resolution Imaging Spectroradiometer (MODIS-A) on board the Aqua platform. The related data are both processed with the SeaWiFS Data Analysis System (SeaDAS, version 6.3 for SeaWiFS and 6.4 for MODIS-A) software package (Fu et al., 1998, Gordon and Wang, 1994, Wang et al., 2005, Ahmad et al., 2010, Bailey et al., 2010). Consistently with MERIS and in situ data, also SeaWiFS and MODIS-A $L_{\mathrm{WN}}$ are corrected for the off-nadir viewing angle and anisotropy of in-water light distribution.

\subsection{In situ data}

Since the launch of Envisat, systematic in situ measurements have been performed across the various European seas in support of MERIS validation activities. These include AERONET-OC time series of multi-spectral $L_{\mathrm{WN}}$ and aerosol optical thickness $\tau_{\mathrm{a}}$ determined from measurements performed through autonomous radiometer systems deployed on fixed platforms in coastal regions (Zibordi et al., 2009a, 2010). Relevant AERONET-OC sites for the study are the Acqua Alta Oceanographic Tower (AAOT) in the northern Adriatic Sea (since 2002), the Gustaf Dalen Lighthouse Tower (GDLT) in the northern Baltic Proper (since 2005), the Helsinki Lighthouse (HLT) in the Gulf of Finland (since 2006) and the Gloria platform (GLR) in the western Black Sea (since 2010).

In addition to AERONET-OC, comprehensive measurements of seawater optical properties, pigments and total suspended matter concentrations, were performed in European seas within the framework of the BiOMaP and CoASTS 
programs. These field activities were primarily established to support bio-optical modeling for optically complex waters (Zibordi and Berthon 2001, Berthon and Zibordi 2004; D'Alimonte et al., 2007, 2012) and to sustain the comprehensive validation of satellite ocean color products (Mélin et al., 2005, 2007). While BiOMaP measurements are performed from oceanographic ships across the major European seas (Zibordi et al., 2011), CoASTS measurements are performed at the AAOT for a few days several times a year by applying the same methods and instruments as in BiOMaP (Berthon et al., 2002, Zibordi et al., 2002). The combined BiOMaP and CoASTS measurements provide comprehensive data from a number of geographic regions exhibiting a variety of bio-optical environments: (i) the Eastern Mediterranean Sea (EMED), the Ligurian Sea (LIGS), and the Iberian Shelf (ISHL), characterized by oligotrophic and mesotrophic case1 waters; (ii) the northern Adriatic Sea (NADR), the western Black Sea (BLKS) and the North Sea (NORS), with case-2 waters exhibiting a variety of concentrations of detritus particles from river discharge or tidal resuspension; and (iii) the Baltic Sea (BLTS), with case-2 waters dominated by high concentrations of dissolved humic matter.

AERONET-OC, BiOMaP and CoASTS radiometric measurements are performed with $10 \mathrm{~nm}$ bandwidth at center wavelengths of relevance for ocean color applications. These are 412, 443, 488, 551, 670 $\mathrm{nm}$ (and recently the additional $531 \mathrm{~nm}$ ) for AERONET-OC, and 412, 443, 490, $510,555,670 \mathrm{~nm}$ for BiOMaP and CoASTS. High accuracy and traceability of AERONET-OC, BiOMaP and CoASTS in situ $L_{\mathrm{WN}}$ are supported through regular pre- and postdeployment instruments calibration, rigorous application of measurement protocols, standardization of data processing and quality assurance (Zibordi et al., 2009a, 2011). Uncertainties for BiOMaP and CoASTS $L_{\mathrm{WN}}$ determined through in-water radiometry have been estimated by accounting for contributions from: absolute in-air calibration and immersion factor; correction coefficients applied to remove instrument self-shading, superstructure perturbations and effects of the anisotropy of the in-water light distribution; determination of total downward irradiance; determination of subsurface values from in-water profile measurements; wave induced perturbations; and seawater variability and illumination changes during measurements. Similarly, uncertainties for AERONET-OC $L_{\mathrm{WN}}$ determined through above-water radiometry have been estimated by accounting for contributions from in-air absolute calibration; correction factors applied to remove the effects of off-nadir viewing angle and anisotropy of the in-water light distribution; input processing quantities like the atmospheric diffuse transmittance and the sea surface reflectance; wave induced perturbations; and changes in seawater optical properties and illumination conditions during measurements.

Results from uncertainty analysis for $L_{\mathrm{WN}}$ indicate values of $4-5 \%$ at the blue-green center wavelengths for all the considered in situ data. Differently, uncertainties increase up to $\sim 6 \%$ for BiOMaP and CoASTS, and up to $\sim 8 \%$, for AERONET-OC $L_{\mathrm{WN}}$ in the red spectral region (Zibordi and Voss, 2010). These uncertainty estimates are fully supported by instruments/methods intercomparisons, when accounting for the combined uncertainties of the compared data (Zibordi, 2012, Zibordi et al., 2012a).

Different from $L_{\mathrm{WN}}$, uncertainties affecting in situ data products such as pigment indices, TSM and $a_{\mathrm{dg}}(443)$ are less consolidated. By recalling that concentrations of phytoplankton pigments were obtained through High Performance Liquid Chromatography (HPLC) by the method detailed in Canuti and Berthon (2010), recent unpublished results from intercomparisons involving various European laboratories indicate average differences of $\sim 7 \%$ for total chlorophyll $a$. Reproducibility figures were determined for TSM and $a_{\mathrm{dg}}(443)$ from the analysis of replicate samples collected in the northern Adriatic Sea (Zibordi et al., 2002). The reproducibility of TSM values, as determined from the net weight of the particles collected on glass fiber filters $(\mathrm{GF} / \mathrm{F})$ with average pore size of $0.7 \mu \mathrm{m}$, indicates mean differences of $14 \%$ with mean concentrations of $0.9 \pm 0.4 \mathrm{mg} \mathrm{L}^{-1}$. Mean value for the reproducibility of $a_{\mathrm{dg}}(443)$ is approximately $20 \%$. This is estimated from values of $16 \%$ related to reproducibility of the absorption coefficient of colored dissolved organic matter (with mean value of $0.10 \pm 0.03 \mathrm{~m}^{-1}$ ) and of $9 \%$ for the absorption coefficient of particles (including both pigmented and non-pigmented particles, with mean value of $\left.0.09 \pm 0.05 \mathrm{~m}^{-1}\right)$.

\subsection{Data comparison}

Match-ups for statistical analysis have been constructed with in situ and satellite data products collected within a maximum time delay $\Delta \mathrm{t}$ from each other. MERIS, SeaWiFS and MODIS-A match-up data have been computed from the average of the $3 \times 3$ pixel values centered at measurement stations or sites. These averages have been retained for comparison when none of the nine pixels was affected by a viewing angle larger than $60^{\circ}$ or Sun zenith angle larger than $70^{\circ}$; the coefficient of variation (i.e. the ratio of standard deviation to average) of $L_{\mathrm{WN}}$ computed for the nine pixels was lower than $20 \%$ at $490 \mathrm{~nm}$; and the general flags indicating cloud or Sun glint contamination were not raised.

When considering MERIS case- 1 data products, additional exclusion criteria included the so-called PCD 1-13 flags, which - if raised - indicate lack of confidence on $L_{\mathrm{WN}}$, and the PCD 15 flag indicating lack of confidence on algal-1 products. In the case of MERIS case- 2 data products, the exclusion criteria are the so-called PCD 16 and PCD 17 flags, which indicate at least one of the following failing conditions: (i) out of scope top-of-atmosphere radiances; (ii) out of scope output from the neural network atmospheric correction; and/or (iii) geophysical products close to maximum or minimum allowed output values. 
Table 1. Statistical results from the analysis of MERIS (2rd Reprocessing) and AERONET-OC $L_{\mathrm{WN}}$, and their ratios at specific center wavelengths for the match-ups determined at the AAOT with $\Delta t= \pm 1 \mathrm{~h}$. The quantities $|\psi|$ and $\psi$ are in $\%$ while rmsd is in units of the quantity compared ( $L_{\mathrm{WN}}$ or ratio). The number of match-ups $N$, and, the averages of $L_{\mathrm{WN}}$ at $560 \mathrm{~nm}$, aerosol optical thickness $\tau_{\mathrm{a}}$ at $869 \mathrm{~nm}$, and Sun zenith angles $\theta_{0}$ from in situ data, are given in the first column (where the \pm values indicate the standard deviation).

\begin{tabular}{llrrrrrrrr}
\hline MERIS & & 413 & 443 & 490 & 560 & 665 & $443 / 560$ & $490 / 560$ & $665 / 560$ \\
\hline$N=160$ & $|\psi|$ & 69 & 36 & 17 & 15 & 44 & 24 & 9 & 35 \\
$L_{\mathrm{WN}}(560)=1.1 \pm 0.50$ & $\psi$ & +55 & +17 & +11 & +7 & -4 & +16 & +3 & -16 \\
$\tau_{\mathrm{a}}(560)=0.20 \pm 0.16$ & $\mathrm{rmsd}$ & 0.61 & 0.43 & 0.28 & 0.19 & 0.06 & 0.31 & 0.16 & 0.06 \\
$\theta_{0}=55 \pm 12$ & $r^{2}$ & 0.19 & 0.46 & 0.80 & 0.90 & 0.82 & 0.58 & 0.82 & 0.38 \\
\hline
\end{tabular}

Table 2. Statistical results from the analysis of MERIS (3rd Reprocessing) and AERONET-OC $L_{\mathrm{WN}}$, and their ratios at specific center wavelengths for the match-ups determined at AAOT with $\Delta t= \pm 1 \mathrm{~h}$. Symbols and units are the same as in Table 1 .

\begin{tabular}{llrrrrrrrr}
\hline MERIS & & 413 & 443 & 490 & 560 & 665 & $443 / 560$ & $490 / 560$ & $665 / 560$ \\
\hline$N=86$ & $|\psi|$ & 48 & 29 & 14 & 12 & 33 & 24 & 8 & 27 \\
$L_{\mathrm{WN}}(560)=1.2 \pm 0.5$ & $\psi$ & -40 & -23 & -8 & -2 & -16 & -23 & -6 & -18 \\
$\tau_{\mathrm{a}}(560)=0.13 \pm 0.09$ & $\mathrm{rmsd}$ & 0.43 & 0.36 & 0.24 & 0.17 & 0.06 & 0.27 & 0.12 & 0.05 \\
$\theta_{0}=57 \pm 11$ & $r^{2}$ & 0.43 & 0.71 & 0.88 & 0.91 & 0.80 & 0.68 & 0.90 & 0.37 \\
\hline
\end{tabular}
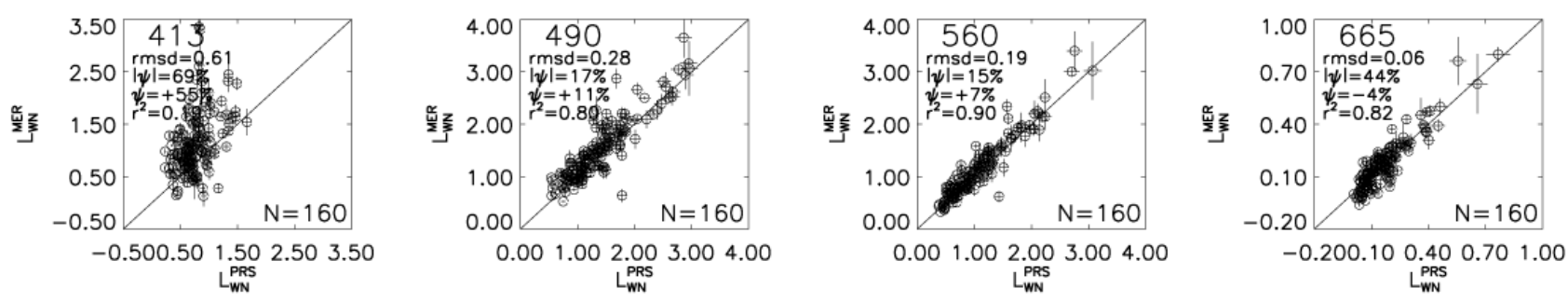

Fig. 1. Scatter plot of MERIS (MER) versus AERONET-OC (PRS) $L_{\mathrm{WN}}$ match-ups at selected center wavelengths determined at the AAOT with $\Delta t= \pm 1 \mathrm{~h}$. MER $L_{\mathrm{WN}}$ were generated from the 2 nd Reprocessing. $N$ indicates the number of match-ups, $L_{\mathrm{WN}}$ and rmsd are in units of $\mathrm{mW} \mathrm{cm}{ }^{-2} \mu \mathrm{m}^{-1} \mathrm{sr}^{-1},|\psi|$ is the mean of absolute percent differences while $\psi$ is the mean of percent differences, and $r^{2}$ is the determination coefficient.
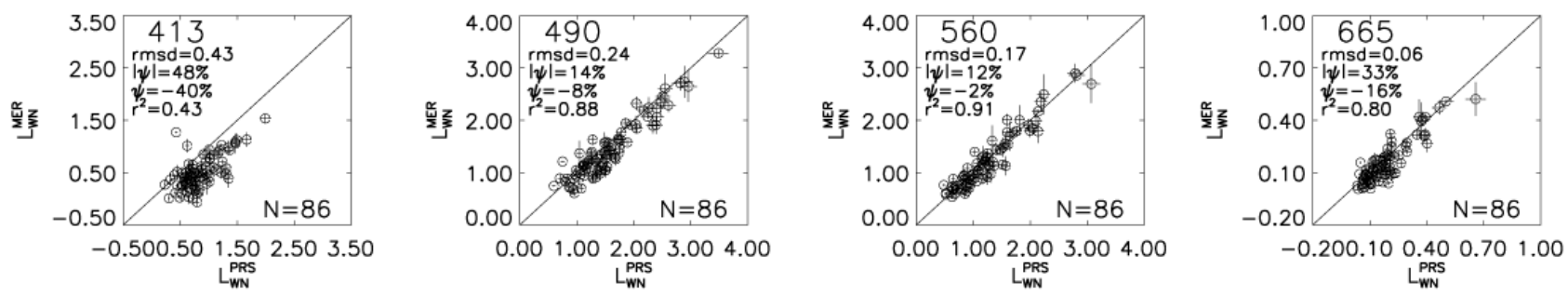

Fig. 2. As in Fig. 1 but for the 3rd Reprocessing. 
Table 3. Statistical results from the analysis of MERIS (2nd Reprocessing) and AERONET-OC $L_{\mathrm{WN}}$, and their ratios at specific center wavelengths for the match-ups determined at AAOT with $\Delta t= \pm 1 \mathrm{~h}$. The analysis has been restricted to the 64 match-ups common to both the 2nd and 3rd Reprocessing. Symbols and units are the same as in Table 1.

\begin{tabular}{llrrrrrrrr}
\hline MERIS & & 413 & 443 & 490 & 560 & 665 & $443 / 560$ & $490 / 560$ & $665 / 560$ \\
\hline$N=64$ & $|\psi|$ & 52 & 28 & 14 & 12 & 33 & 18 & 6 & 23 \\
$L_{\mathrm{WN}}(560)=1.2 \pm 0.5$ & $\psi$ & +41 & +20 & +9 & +6 & +9 & +12 & +13 & -1 \\
$\tau_{\mathrm{a}}(560)=0.13 \pm 0.10$ & rmsd & 0.44 & 0.33 & 0.24 & 0.17 & 0.06 & 0.20 & 0.11 & 0.04 \\
$\theta_{0}=57 \pm 11$ & $r^{2}$ & 0.33 & 0.62 & 0.86 & 0.90 & 0.78 & 0.63 & 0.88 & 0.30 \\
\hline
\end{tabular}

Table 4. Statistical results from the analysis of MERIS (3rd Reprocessing) and AERONET-OC $L_{\mathrm{WN}}$, and their ratios at specific center wavelengths for the match-ups determined at AAOT with $\Delta t= \pm 1 \mathrm{~h}$. The analysis has been restricted to the 64 match-ups common to both the 2nd and 3rd Reprocessing. Symbols and units are the same as in Table 1.

\begin{tabular}{llrrrrrrrr}
\hline MERIS & & 413 & 443 & 490 & 560 & 665 & $443 / 560$ & $490 / 560$ & $665 / 560$ \\
\hline$N=64$ & $|\psi|$ & 40 & 30 & 14 & 12 & 36 & 25 & 8 & 28 \\
$L_{\mathrm{WN}}(560)=1.2 \pm 0.5$ & $\psi$ & -40 & -24 & -8 & -2 & -16 & -23 & -6 & -17 \\
$\tau_{\mathrm{a}}(560)=0.13 \pm 0.10$ & rmsd & 0.43 & 0.36 & 0.25 & 0.18 & 0.06 & 0.27 & 0.12 & 0.05 \\
$\theta_{0}=57 \pm 11$ & $r^{2}$ & 0.35 & 0.65 & 0.85 & 0.88 & 0.74 & 0.67 & 0.90 & 0.26 \\
\hline
\end{tabular}

The assessment of satellite versus in situ data for the generic quantity $\Im$ is presented through the average of percent differences, $\psi$, and the average of absolute (unsigned) percent differences, $|\psi|$, of $N$ match-ups.

Specifically, the value of $\psi$ is computed through

$\psi=\frac{1}{N} \sum_{i=1}^{N} \psi_{i}$

where $i$ is the match-up index, and $\psi_{i}$ is

$\psi_{i}=100 \frac{\Im^{S}(i)-\Im^{R}(i)}{\Im^{R}(i)}$

with the superscripts $S$ and $R$ indicating the satellite derived and the in situ reference data, respectively. The absolute values of $\psi_{i},\left|\psi_{i}\right|$, are applied to determine the average of absolute percent differences $|\psi|$ through

$|\psi|=\frac{1}{N} \sum_{i=1}^{N}\left|\psi_{i}\right|$.

The quantity $\psi$ determines the bias, while $|\psi|$ indicates the scattering of data points. The root mean square of differences (rmsd) and the determination coefficient $r^{2}$ are additional statistical quantities utilized to discuss results from the match-up analysis.

The former statistical indices are expected to provide accurate results with a significant number of match-ups that would minimize the effects of (i) differences between in situ and satellite spatial resolutions, (ii) sub-pixel spatial variability in satellite observations and (iii) temporal changes in seawater and atmospheric optical properties occurring between satellite and in situ data collection.

\section{Intercomparison results}

The assessment is separately performed for MERIS case-1 and case- 2 water products utilizing match-ups constructed by applying the criteria listed in Sect. 2.3, regardless of any independent classification of the water type.

\subsection{Case- 1 water data products}

Match-ups of MERIS and in situ AERONET-OC $L_{\mathrm{WN}}$ data have been constructed with $\Delta t= \pm 1 \mathrm{~h}$ for the AAOT site in the northern Adriatic Sea. Differences in center wavelengths between in situ and satellite-derived $L_{\mathrm{WN}}$ have been minimized through band-shift corrections of the in situ data in agreement with the scheme outlined in Zibordi et al., (2009b). Results from the match-up analysis are illustrated in Figs. 1 and 2. Specifically, scatter plots are given at relevant ocean color center wavelengths (i.e. 413, 490, 560 and $665 \mathrm{~nm}$ ) for products resulting from the 2nd and 3rd Reprocessing (validation statistics are also summarized in Tables 1 and 2 for an extended set of center wavelengths and band ratios). In agreement with previous analyses (Zibordi et al., 2006; Antoine et al., 2008), MERIS $L_{\mathrm{WN}}$ data from the 2nd Reprocessing exhibit a significant positive bias at the blue center wavelengths indicated by $\psi$ equal to $+55 \%$ at $413 \mathrm{~nm}$, decreasing to $+11 \%$ at $490 \mathrm{~nm},+7 \%$ at $560 \mathrm{~nm}$, and $-4 \%$ at $665 \mathrm{~nm}$. Differently, the 3rd Reprocessing exhibits a significant negative bias at the blue center wavelengths with $\psi$ equal to $-40 \%$ at $413 \mathrm{~nm}$, decreasing to $-8 \%$ at $490 \mathrm{~nm},-2 \%$ at $560 \mathrm{~nm}$ and then increasing to $-16 \%$ at $665 \mathrm{~nm}$. The pronounced decrease in MERIS $L_{\mathrm{WN}}$ from the 2nd to the 3rd Reprocessing is accompanied by an appreciable decrease in rmsd (e.g., from 

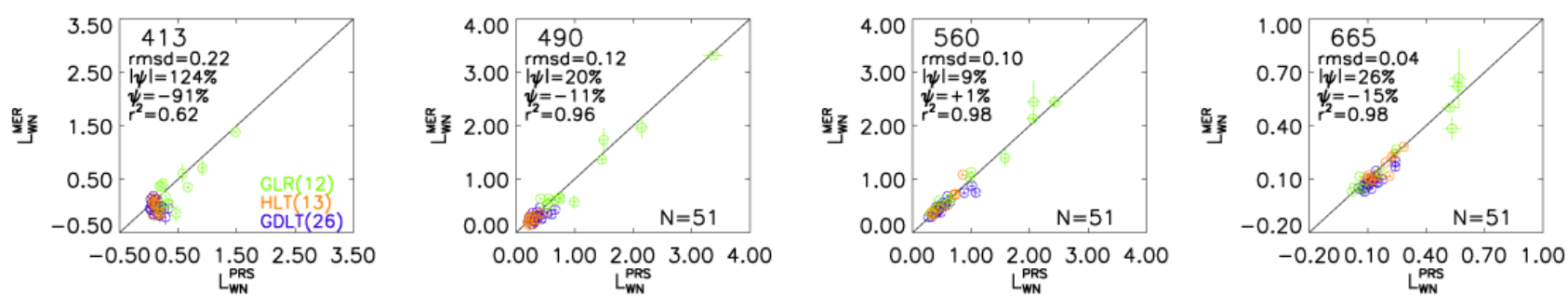

Fig. 3. Scatter plots of MERIS (MER) versus AERONET-OC (PRS) $L_{\mathrm{WN}}$ match-ups at selected center wavelengths for different sites with $\Delta t= \pm 2 \mathrm{~h}$. Symbols and units are the same as in Fig. 1. Different colors identify data from different sites (GLR in the Western Black Sea, HLT in the Gulf of Finland, GDLT in the northern Baltic Proper).
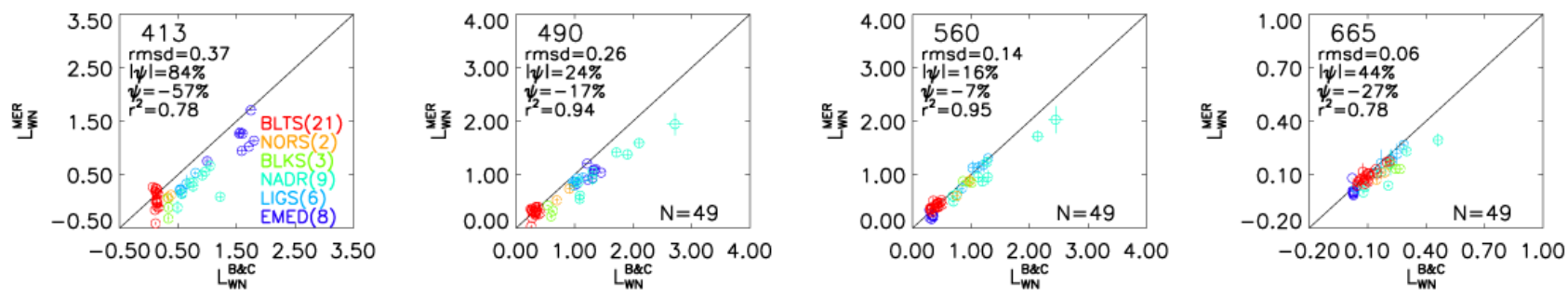

Fig. 4. Scatter plots of MERIS (MER) versus BiOMaP and CoASTS (B\&C) $L_{\mathrm{WN}}$ match-ups at selected center wavelengths determined with $\Delta t= \pm 4 \mathrm{~h}$. Symbols and units are the same as in Fig. 1. Different colors identify match-ups from different seas: Baltic Sea (BLTS), North Sea (NORS), Black Sea (BLKS), northern Adriatic Sea (NADR), Ligurian Sea (LIGS), and Eastern Mediterranean Sea (EMED).

Table 5. Statistical results from the analysis of MERIS (3rd Reprocessing) and AERONET-OC $L_{\mathrm{WN}}$, and their ratios at specific center wavelengths for the match-ups determined at the GDLT and HLT with $\Delta t= \pm 2 \mathrm{~h}$. Symbols and units are the same as in Table 1 .

\begin{tabular}{llrrrrrrrr}
\hline MERIS & & 413 & 443 & 490 & 560 & 665 & $443 / 560$ & $490 / 560$ & $665 / 560$ \\
\hline$N=39$ & $|\psi|$ & 141 & 67 & 21 & 8 & 24 & 66 & 17 & 22 \\
$L_{\mathrm{WN}}(560)=0.5 \pm 0.2$ & $\psi$ & -111 & -54 & -14 & -2 & -23 & -55 & -13 & -22 \\
$\tau_{\mathrm{a}}(560)=0.08 \pm 0.04$ & rmsd & 0.21 & 0.17 & 0.10 & 0.08 & 0.04 & 0.29 & 0.14 & 0.07 \\
$\theta_{0}=46 \pm 6$ & $r^{2}$ & 0.11 & 0.03 & 0.39 & 0.82 & 0.79 & 0.03 & 0.58 & 0.58 \\
\hline
\end{tabular}

Table 6. Statistical results from the analysis of MERIS (3rd Reprocessing) and AERONET-OC $L_{\mathrm{WN}}$, and their ratios at specific center wavelengths for the match-ups determined at GLR with $\Delta t= \pm 2 \mathrm{~h}$. Symbols and units are the same as in Table 1.

\begin{tabular}{llrrrrrrrr}
\hline MERIS & & 413 & 443 & 490 & 560 & 665 & $443 / 560$ & $490 / 560$ & $665 / 560$ \\
\hline$N=12$ & $|\psi|$ & 67 & 36 & 15 & 11 & 31 & 28 & 11 & 22 \\
$L_{\mathrm{WN}}(560)=1.3 \pm 1.0$ & $\psi$ & -24 & -12 & -1 & +7 & +12 & -20 & -9 & +2 \\
$\tau_{\mathrm{a}}(560)=0.15 \pm 0.09$ & rmsd & 0.27 & 0.21 & 0.17 & 0.14 & 0.06 & 0.18 & 0.11 & 0.04 \\
$\theta_{0}=50 \pm 8$ & $r^{2}$ & 0.67 & 0.89 & 0.96 & 0.99 & 0.98 & 0.81 & 0.95 & 0.88 \\
\hline
\end{tabular}



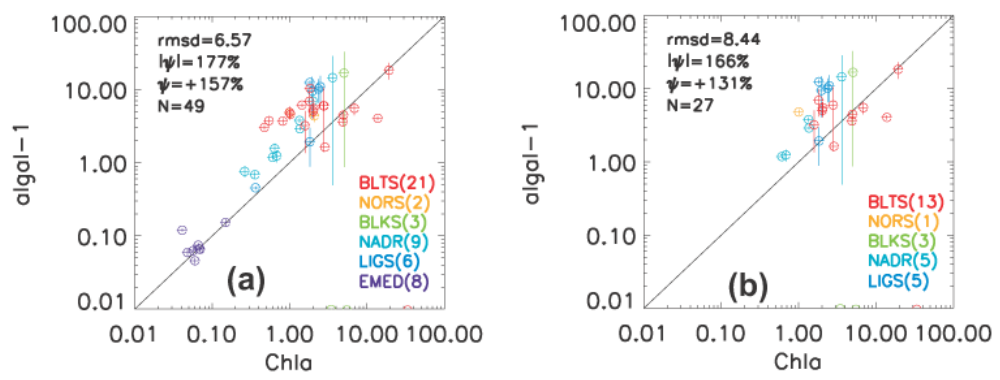

Fig. 5. Scatter plot of MERIS derived algal-1 pigment index (algal-1) and in situ total chlorophyll $a$ (Chla) in units of $\mu g \mathrm{~L}^{-1}$ quantified through High Performance Liquid Chromatography (HPLC) for match-ups determined with $\Delta t= \pm 4$ h. Panels (a) and (b) display match-ups constructed neglecting and accounting for confidence flag PCD-15, respectively. Colors indicate match-ups from different seas in agreement with notations applied in Fig. 4).
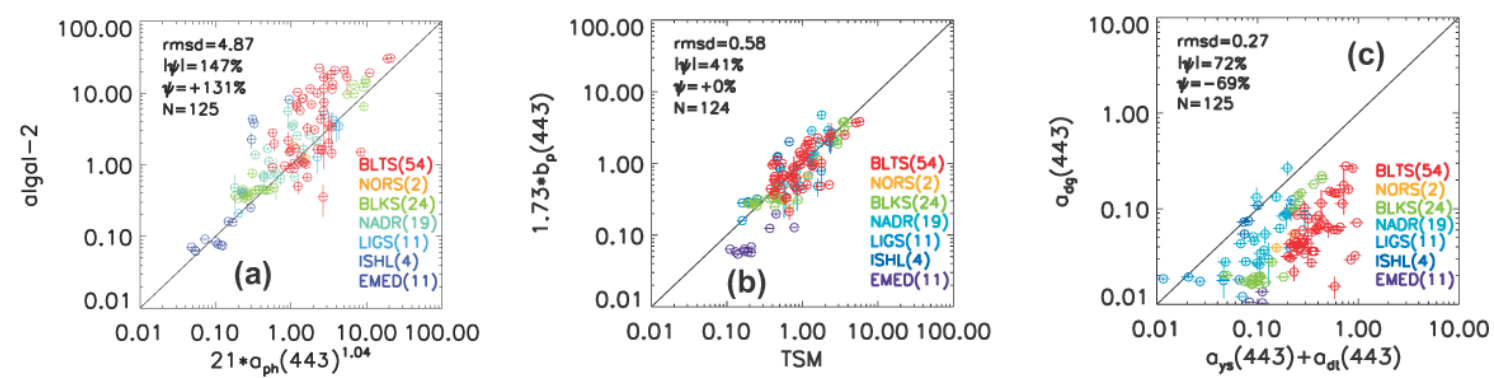

Fig. 6. Scatter plot of: algal-2 pigment index in units of $\mu \mathrm{L}^{-1}$ and equivalent index determined from in situ values of the absorption coefficient of pigmented particles at $443 \mathrm{~nm}, a_{\mathrm{ph}}(443)$ in units of $\mathrm{m}^{-1}$ (a); MERIS TSM values determined from particle scattering at $443 \mathrm{~nm}, b_{\mathrm{p}}(443)$ in units of $\mathrm{m}^{-1}$, with respect to in situ gravimetric determinations (TSM) in units of $\mathrm{mg} \mathrm{L}^{-1}$ (b); absorption coefficient $a_{\mathrm{dg}}(443)$ in units of $\mathrm{m}^{-1}$ with respect to combined values of in situ $a_{\mathrm{ys}}(443)$ and $a_{\mathrm{dt}}(443)$ (c). All match-ups have been constructed with $\Delta t= \pm 4 \mathrm{~h}$. Different colors identify match-ups from different seas: Baltic Sea (BLTS), North Sea (NORS), Black Sea (BLKS), northern Adriatic Sea (NADR), Ligurian Sea (LIGS), Iberian Shelf (ISHL) and Eastern Mediterranean Sea (EMED).

0.61 to $0.43 \mathrm{~mW} \mathrm{~cm}^{-2} \mu^{-1} \mathrm{sr}^{-1}$ at $413 \mathrm{~nm}$ ) and $|\psi|$ (e.g., from $69 \%$ to $48 \%$ at $413 \mathrm{~nm}$ ), and an increase in $r^{2}$ (e.g, from 0.19 to 0.43 at $413 \mathrm{~nm}$ ). The former changes in matchup statistics from the 2nd to the 3rd Reprocessing are translated in changes affecting the band ratios (see Tables 1 and 2 ), as clearly shown by the values involving the blue center wavelengths.

The large reduction of match-ups obtained for the two processing applying the same construction criteria is, however, quite striking: 160 match-ups for the 2 nd Reprocessing referring to data from 2002 to 2009 , and 86 for the 3rd Reprocessing referring to data from 2002 to 2011 . This is likely explained by changes affecting the confidence flags PCD 113. When restricting the intercomparison to match-ups common to both the 2nd and 3rd Reprocessing (see Tables 3 and 4), results do not exhibit significant differences for MEGS8 but indicate better performance for MEGS-7 with respect to the statistics given in Table 2 (e.g., the bias at $412 \mathrm{~nm}$ decreases to $+41 \%$ from $+55 \%$ ). This improved performance may be explained by the application to MEGS-7 products of the more stringent quality checks included in the MEGS-8 processing. Still, results confirm the systematic differences between the 2nd and 3rd MERIS data Reprocessing indicating overestimate of MEGS-7 $L_{\mathrm{WN}}$ data and underestimate of MEGS-8 $L_{\mathrm{WN}}$.

Results from the AAOT intercomparison presented in Fig. 2 are complemented with data from different European AERONET-OC sites (see Fig. 3). These include GLR in the western Black Sea and, GDLT and HLT in the Baltic Sea. For this analysis $\Delta t$ has been extended to $\pm 2 \mathrm{~h}$ to increase the number of match-ups at sites located in regions exhibiting less favorable measurement conditions than the AAOT. Validation statistics are separately presented for the Baltic (GDLT and HLT) and Black Sea (GLR) sites in Tables 5 and 6, respectively. Results for GDLT and HLT exhibit values of $|\psi|$ and $\psi$ more pronounced at the blue center wavelengths than those determined for the AAOT. This finding and the very low $r^{2}$ at 413 and $443 \mathrm{~nm}$, are explained by the small values of Baltic Sea $L_{\mathrm{WN}}$ (see Zibordi et al., 2011). Despite the high $r^{2}$, results for GLR show values of $|\psi|$ more pronounced than those determined for the AAOT while $\psi$ exhibits a marked bias with values ranging from $-24 \%$ at $413 \mathrm{~nm}$ to $+12 \%$ at $667 \mathrm{~nm}$. These results, however, need to 
Table 7. Statistical results from the analysis of SeaWiFS and AERONET-OC $L_{\mathrm{WN}}$, and their ratios at specific center wavelengths for the match-ups determined at the AAOT with $\Delta t= \pm 1 \mathrm{~h}$. Symbols and units are the same as in Table 1.

\begin{tabular}{llrrrrrrrr}
\hline SeaWiFS & & 412 & 443 & 490 & 555 & 670 & $443 / 555$ & $490 / 555$ & $670 / 555$ \\
\hline$N=468$ & $|\psi|$ & 29 & 21 & 12 & 12 & 50 & 17 & 7 & 44 \\
$L_{\mathrm{WN}}(560)=1.1 \pm 0.5$ & $\psi$ & +7 & +9 & -1 & -1 & -21 & +10 & +1 & -28 \\
$\tau_{\mathrm{a}}(560)=0.16 \pm 0.10$ & rmsd & 0.25 & 0.24 & 0.22 & 0.23 & 0.07 & 0.18 & 0.13 & 0.06 \\
$\theta_{0}=42 \pm 13$ & $r^{2}$ & 0.50 & 0.72 & 0.84 & 0.84 & 0.73 & 0.77 & 0.87 & 0.44 \\
\hline
\end{tabular}

Table 8. Statistical results from the analysis of MODIS-A and AERONET-OC $L_{\mathrm{WN}}$, and their ratios at specific center wavelengths for the $\mathrm{N}$ available match-ups determined at the AAOT with $\Delta t= \pm 1 \mathrm{~h}$. Symbols and units are the same as in Table 1 .

\begin{tabular}{llrrrrrrrr}
\hline MODIS-A & & 413 & 443 & 488 & 547 & 667 & $443 / 547$ & $488 / 547$ & $667 / 547$ \\
\hline$N=567$ & $|\psi|$ & 27 & 16 & 11 & 11 & 49 & 12 & 6 & 47 \\
$L_{\mathrm{WN}}(547)=1.1 \pm 0.6$ & $\psi$ & -15 & -2 & -4 & -6 & -36 & +4 & +2 & -38 \\
$\tau_{\mathrm{a}}(560)=0.15 \pm 0.09$ & $\mathrm{rmsd}$ & 0.24 & 0.18 & 0.17 & 0.15 & 0.05 & 0.14 & 0.09 & 0.05 \\
$\theta_{0}=44 \pm 12$ & $r^{2}$ & 0.59 & 0.81 & 0.92 & 0.93 & 0.84 & 0.76 & 0.91 & 0.52 \\
\hline
\end{tabular}

be considered with caution because of the small number of match-ups included in the analysis (12).

An additional evaluation of MERIS $L_{\mathrm{WN}}$ data is performed applying the BiOMaP and CoASTS data with $\Delta t= \pm 4 \mathrm{~h}$. Results presented in Fig. 4 indicate MERIS $L_{\mathrm{WN}}$ with a larger negative bias with respect to those determined at the AERONET-OC sites. These differences are partially explained by a seasonal dependence affecting the satellite data products (Zibordi et al., 2012b). In fact while the collection of AERONET-OC data spans over all seasons, BiOMaP measurements are commonly performed during spring and summer. Additionally, 15 match-ups from the western Black Sea for July 2011 were not included in the analysis because of potential failure of MEGS-8 in flagging MERIS data products affected by sun-glint perturbations. This limitation of the processing code for the specific sample data is suggested by an evident overestimate of satellite derived with respect to the in situ $L_{\mathrm{WN}}$ spectra in spatially homogeneous open sea waters.

The evaluation of higher level MERIS products is performed with the BiOMaP and CoASTS data, and illustrated in Fig. 5. The scatter plot for the algal-1 pigment index is displayed in Fig. 5a accounting for all match-ups regardless of the PCD 15 confidence flag. Results indicate a substantial overestimate of MERIS products data with $\psi$ equal to $+157 \%$. Still, qualitative good agreement between satellite and in situ data is observed for the Eastern Mediterranean Sea oligotrophic waters. Comparable overestimate of algal1 values (i.e. $+131 \%$ ) is shown in Fig. $5 b$ when accounting for the PCD 15 confidence flag significantly reducing the number of match-ups. Surprisingly, the use of the confidence flag leads to the exclusion of match-ups from the Eastern Mediterranean Sea oligotrophic waters.

\subsection{Case-2 water data products}

The $R_{\mathrm{rs}}$ resulting from the case- 2 water processing are not included among the standard MERIS level-2 products. Because of this, an assessment of the primary radiometric data products from the case- 2 water processor is not performed. Nevertheless, it is reported that a dedicated study on the evaluation of MEGS-8 atmospheric corrections restricted to AERONET-OC data from the AAOT, indicates a reduced capability of the case- 2 water neural network atmospheric correction to capture the variability displayed by the in situ $R_{\mathrm{rs}}$ data at 413, 443 and $490 \mathrm{~nm}$ (Kajiyama et al., 2013). It is however noted that a successive development of the neural network atmospheric correction scheme has shown much improved performance (Müller et al., 2013).

Derived case-2 water products are algal-2, TSM and $a_{\mathrm{dg}}(443)$. Match-up analyses for these derived products have been constructed using $\Delta t= \pm 4 \mathrm{~h}$ and are illustrated in Fig. 6. Results for algal-2 are displayed in Fig. 6a and indicate a significant overestimate of the pigment index with respect to the in situ data (quantified by $\psi$ equal to $+131 \%$ ). Exceptions are match-ups for the Eastern Mediterranean Sea oligotrophic waters and the Western Black Sea moderately turbid waters exhibiting a qualitative good agreement with in situ data. It is remarked that the algal-1 and algal-2 pigment indices, showing comparable biases with respect to in situ data, are determined from fully independent processing (that also explains the different number of match-ups).

Results for TSM and $a_{\mathrm{dg}}(443)$ match-up analysis are presented in Fig. $6 \mathrm{~b}$ and c, respectively. While TSM shows a significant agreement between satellite and in situ measurements with $\psi$ equal to 0 (even though differences are certainly large for the Eastern Mediterranean Sea waters), results for $a_{\mathrm{dg}}(443)$ indicate a broad underestimate with $\psi$ equal to $-69 \%$. 

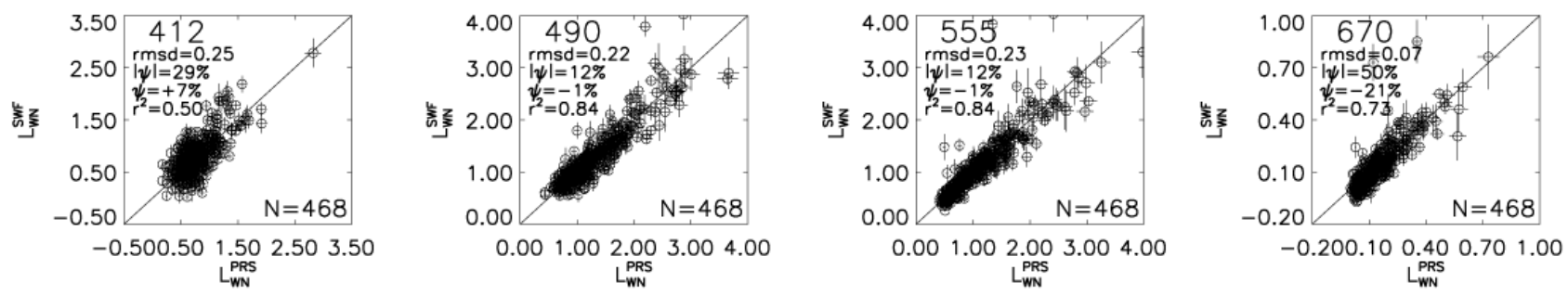

Fig. 7. Scatter plots of SeaWiFS (SWF) versus AERONET-OC (PRS) $L_{\mathrm{WN}}$ match-ups at selected center wavelengths determined at the AAOT with $\Delta t= \pm 1 \mathrm{~h}$. Symbols and units are the same as in Fig. 1.
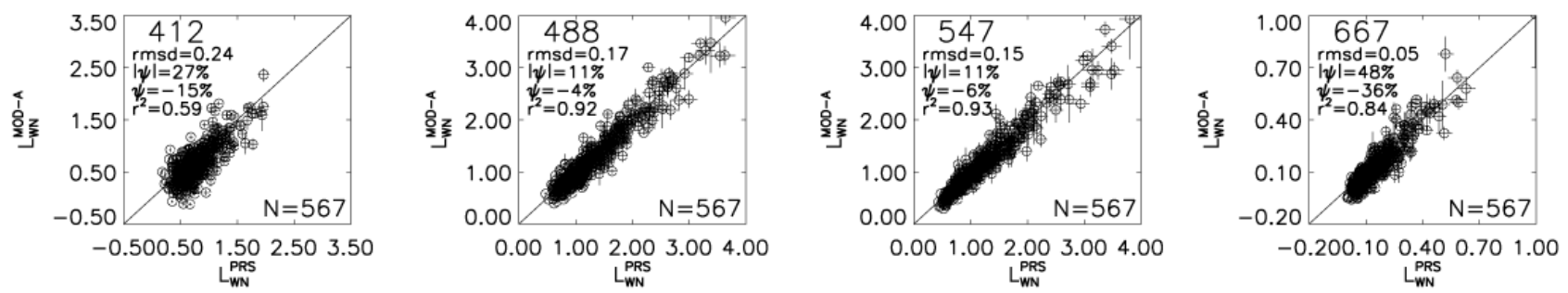

Fig. 8. As in Fig. 7 but for MODIS-A (MOD-A).
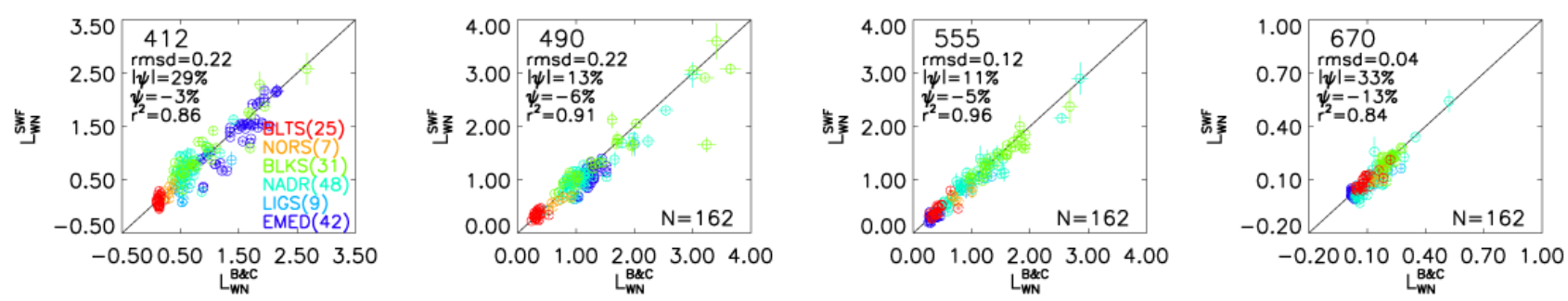

Fig. 9. Scatter plots of SeaWiFS (SWF) versus BiOMaP and CoASTS (B\&C) $L_{\mathrm{WN}}$ at selected center wavelengths for match-ups determined with $\Delta t= \pm 4 \mathrm{~h}$. Symbols and units are the same as in Fig. 1. Different colors identify different seas: Baltic Sea (BLTS), North Sea (NORS), Black Sea (BLKS), northern Adriatic Sea (NADR), Ligurian Sea (LIGS), Iberian Shelf (ISHL) and Eastern Mediterranean Sea (EMED).
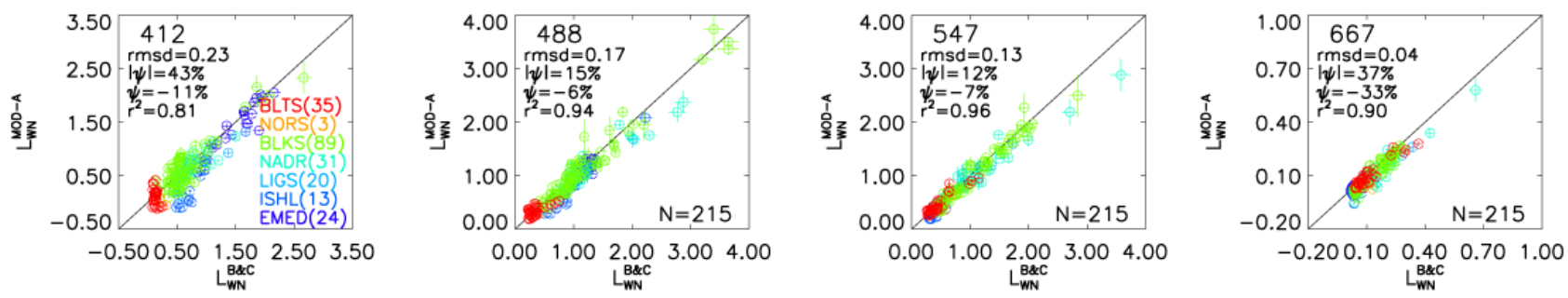

Fig. 10. Same as in Fig. 9 but for MODIS-A (MOD-A). 

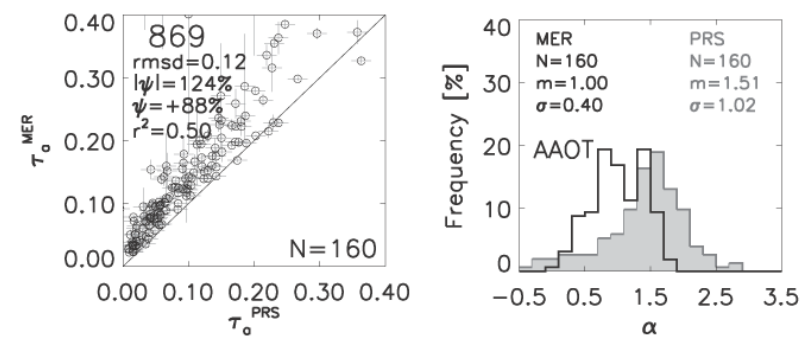

Fig. 11. Scatter plots of MERIS (MER) and AERONET-OC (PRS) $\tau_{\mathrm{a}}(869)$ match-ups for the AAOT determined with $\Delta t= \pm 1 \mathrm{~h}$ (left panel), and corresponding frequency distributions (right panel) of $\alpha$ determined with $\tau_{\mathrm{a}}$ at 779 and $869 \mathrm{~nm}$ from MERIS data and at 670 and $869 \mathrm{~nm}$ from AERONET-OC data. Data are from the 2nd Reprocessing. The horizontal bars in the scatter plot indicate the estimated uncertainty in AERONET-OC $\tau_{\mathrm{a}}$ while vertical bars indicate \pm 1 standard deviation of the $3 \times 3$ values utilized for computing MERIS $\tau_{\mathrm{a}}$. The black characters and lines in the frequency distribution plot, indicate results from the analysis of MERIS data while grey characters and solid bars indicate results from the analysis of AERONET-OC data ( $N$ is the number of match-ups, $m$ is the median and $\sigma$ the standard deviation).

\section{Discussion}

A major objective of satellite ocean color missions is the creation of Climate Data Records (CDRs) of Essential Climate Variables (ECVs). By recalling that current ocean color ECVs include radiometric data (i.e. $L_{\mathrm{WN}}$ or $R_{\mathrm{rs}}$ ) and chlorophyll $a$ concentration (UNFCCC, 2011), where this latter is derived from radiometry, the discussion on MERIS water products is here mostly restricted to $L_{\mathrm{WN}}$ included in the standard data products and determined through application of the case- 1 water data processor. The rationale for this is the basic need for a comprehensive assessment of uncertainty and bias of the primary radiometric products considered for CDRs.

Two elements of discussion are brought: (i) an assessment of ocean color data products from other missions; and (ii) an evaluation of the case-1 water atmospheric correction through the assessment of aerosol data products from the 2 nd and 3rd Reprocessing.

\subsection{Assessment of $L_{\mathrm{WN}}$ data products from other missions}

Outcomes from the analysis of MERIS $L_{\mathrm{WN}}$ illustrated in Fig. 2 are discussed with respect to SeaWiFS and MODIS-A match-ups constructed using AERONET-OC data from the AAOT site. Results are displayed in Figs. 7 and 8, and also summarized in Tables 7 and 8 for an extended set of center wavelengths and band ratios. SeaWiFS match-ups exhibit values of $\psi$ equal to $+7 \%$ at $412 \mathrm{~nm}$, decreasing to $-1 \%$ at $490 \mathrm{~nm}$ and $555 \mathrm{~nm}$, and then increasing to $-21 \%$ at $670 \mathrm{~nm}$. Correspondingly, MODIS-A match-ups exhibit values of $\psi$
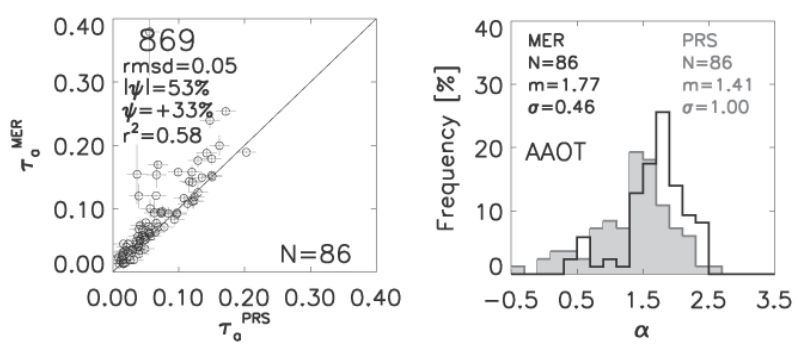

Fig. 12. Same as in Fig. 11, but with data from the 3rd Reprocessing.

equal to $-15 \%$ at $412 \mathrm{~nm},-4 \%$ at $488 \mathrm{~nm},-6 \%$ at $547 \mathrm{~nm}$, and $-36 \%$ at $667 \mathrm{~nm}$. When excluding $412 \mathrm{~nm}$, the relatively similar validation statistics found for SeaWiFS and MODISA are certainly supported by the application of a common atmospheric correction code (i.e. SeaDAS) and equivalent processing solutions. Notable are the number of match-ups and the generally lower values of $|\psi|, \psi$ and rmsd determined for SeaWiFS and MODIS-A with respect to MERIS.

The former findings are supported by the analysis of match-ups constructed using BiOMaP and CoASTS data from various European seas. Related results are presented in Figs. 9 and 10 using $\Delta t= \pm 4 \mathrm{~h}$. Specifically, SeaWiFS match-ups exhibit $\psi$ equal to $-3 \%$ at $412 \mathrm{~nm},-6 \%$ at $490 \mathrm{~nm},-5 \%$ at $555 \mathrm{~nm}$ and $-13 \%$ at a $670 \mathrm{~nm}$. Correspondingly, MODIS-A match-ups show $\psi$ equal to $-11 \%$ at $412 \mathrm{~nm},-6 \%$ at $488 \mathrm{~nm},-7 \%$ at $547 \mathrm{~nm}$, and $-33 \%$ at $667 \mathrm{~nm}$. Differences with respect to the SeaWiFS and MODIS-A match-up analysis presented for the AAOT site and displayed in Figs. 7 and 8, are certainly appreciable. But they are not major when considering the variety of biooptical regions and atmospheric types included in $\mathrm{BiOMaP}$ data, and also the application of different measurement methods for the determination of the in situ $L_{\mathrm{WN}}$ data (i.e., above-water radiometry for AERONET-OC and in-water radiometry for BiOMaP and CoASTS). Additionally, the interannual dependence of biases observed for both SeaWiFS and MODIS-A $L_{\mathrm{WN}}$ (Zibordi et al., 2012b) may play a role in explaining the observed differences, considering the diverse seasonal distribution of AERONET-OC and BiOMaP measurements.

For completeness, it is reported that the processing of MERIS data with SeaDAS version 6.2 (Mélin et al., 2011) shows agreement with in situ data consistent with that determined here for SeaWiFS. Specifically, results from matchups analysis between MERIS data determined with SeaDAS and AERONET-OC data from the AAOT, exhibit biases of $+5 \%$ at 412 and $443 \mathrm{~nm}$, decreasing to $-3 \%$ at $560 \mathrm{~nm}$ and increasing up to $-10 \%$ at $665 \mathrm{~nm}$.

\subsection{Evaluation of MERIS aerosol data products}

Results from SeaWiFS and MODIS-A match-up analysis reinforce the existence of a significant negative bias affecting 

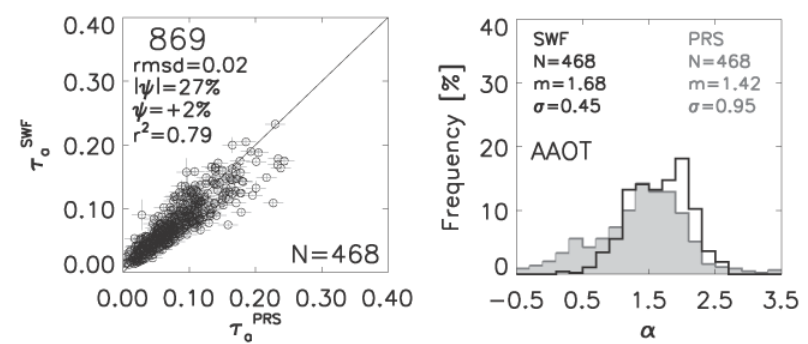

Fig. 13. Scatter plot of SeaWiFS (SWF) versus AERONET-OC (PRS) $\tau_{\mathrm{a}}(869)$ match-ups for the AAOT (left panel) determined with $\Delta t= \pm 1 \mathrm{~h}$ and the corresponding frequency distribution (right panel) of $\alpha$ determined with $\tau_{\mathrm{a}}$ at 765 and $869 \mathrm{~nm}$ from SeaWiFS data and at 670 and $869 \mathrm{~nm}$ from AERONET-OC data. Symbols are the same applied in Fig. 11.

MERIS with respect to in situ $L_{\mathrm{WN}}$ at the blue center wavelengths (mostly 413 and $443 \mathrm{~nm}$ ). The reason for this underestimate is however not obvious. In fact, when considering the changes in MEGS-8 with respect to MEGS-7 (e.g. the introduction of vicarious calibration and a major revision of the bright pixel atmospheric correction scheme) any guess on the reason for the underestimate would be speculative. However, in view of supporting further investigations, results from match-up analysis of the aerosol optical thickness $\tau_{\mathrm{a}}(869)$ and Ångström exponent $\alpha$ are presented for both the 2nd and 3rd Reprocessing. The in situ data applied for this analysis are the standard AERONET $\tau_{\mathrm{a}}$ products (Holben et al., 1998) with expected absolute uncertainty of 0.015 (Eck et al., 1999). Validation results presented in Figs. 11 and 12 for the AAOT site show a clear decrease of the average bias for $\tau_{\mathrm{a}}(869)$ from the 2 nd to the 3 rd Reprocessing with values of $\psi$ decreasing from $+88 \%$ to $+33 \%$. However, notable is the shift of the median of $\alpha$ increasing from 1.00 to 1.77 while the in situ values exhibit a relatively small decrease from 1.51 to 1.41 likely explained by the different number of matchups. This systematic increase in $\alpha$ from the 2 nd to the 3 rd Reprocessing may lead to differences in the determination of the aerosol type and to an overestimate of the atmospheric radiance contribution to the top-of-atmosphere signal, with more pronounced effects at the blue center wavelengths. For the sake of completeness, equivalent match-up analyses are also presented for SeaWiFS and MODIS-A in Figs. 13 and 14. Results indicate a remarkable agreement between SeaWiFS and in situ data with $\psi$ equal to $+2 \%$, and median of $\alpha$ equal to 1.68 for SeaWiFS and 1.42 for AERONET-OC. Results for MODIS-A are equivalent in terms of $\alpha$ (i.e. 1.66 for MODIS-A and 1.42 for AERONET-OC) but exhibit a significant bias for $\tau_{\mathrm{a}}(869)$ as indicated by $\psi$ equal to $+20 \%$.

As already anticipated, an equivalent analysis is not performed for $L_{\mathrm{WN}}$ from the case-2 water neural network atmospheric correction as it is not included in the standard MERIS data products.
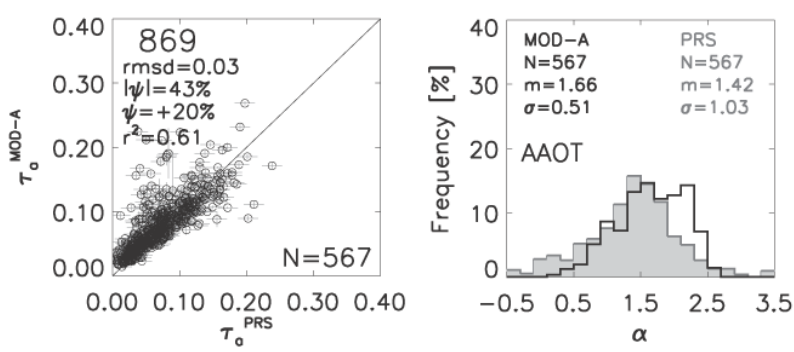

Fig. 14. Same as in Fig. 13 but for MODIS-A with $\alpha$ determined from $\tau_{\mathrm{a}}$ at 748 and $869 \mathrm{~nm}$.

\section{Summary and conclusions}

The assessment of primary and derived MERIS ocean color products from the 3rd Reprocessing for European seas has led to the following results:

- Match-ups of MERIS $L_{\mathrm{WN}}$ from the case-1 water data processor and from AERONET-OC (abovewater) for the AAOT site, indicate a major underestimate at the blue center wavelengths (e.g. $-40 \%$ at $413 \mathrm{~nm}$ in the range of approximately $\left.0.20-1.75 \mathrm{~mW} \mathrm{~cm}^{-2} \mu \mathrm{m}^{-1} \mathrm{sr}^{-1}\right)$. This is confirmed by BioMaP and CoASTS (in-water) radiometry for most of the European seas and by match-up analysis performed for SeaWiFS and MODIS-A data utilizing AERONETOC, BiOMaP and CoASTS data.

- The concentration of pigments indicates a major overestimate in most of the European seas (i.e. $+131 \%$ for both algal-1 and algal-2 in the range of approximately $0.05-20 \mathrm{mg} \mathrm{L}^{-1}$ ). Exceptions, only based on small statistical samples, are the Eastern Mediterranean Sea oligotrophic waters and the Black Sea moderately turbid waters for the algal-2 pigment index.

- The concentration of total suspended matter TSM indicates qualitatively good results with an average bias of $0 \%$ in the range of $0.1-5 \mathrm{mg} \mathrm{L}^{-1}$, even though exhibiting a different accuracy across the various European seas. The worst results are observed for the Eastern Mediterranean Sea oligotrophic waters.

- The combined absorption coefficients of colored dissolved organic matter and non-pigmented particles at $443 \mathrm{~nm}, a_{\mathrm{dg}}(443)$, indicate major underestimates for all the considered European seas (i.e. $-69 \%$ in the range of $\left.0.01-1.0 \mathrm{~m}^{-1}\right)$.

- The aerosol optical thickness at $869 \mathrm{~nm} \tau_{\mathrm{a}}(869)$ at the AAOT coastal site indicates significant overestimate (i.e. $+33 \%$ in the range of $0.0-0.2$ ). The Ångström exponent $\alpha$ also appears overestimated.

The former results lead to the following recommendations: 
1. The vicarious calibration procedure and bright pixel atmospheric correction scheme supporting the case- 1 water data processing should be thoroughly investigated to identify the reasons for the systematic negative bias affecting $L_{\mathrm{WN}}$ (or the equivalent $R_{\mathrm{rs}}$ ) at the blue center wavelengths.

2. Changes in the PCD 1-13 confidence flags generated by the MEGS-8 processor should be reevaluated in view of determining and eventually correcting the reasons for the large increase in the number of $L_{\mathrm{WN}}$ data excluded from the case- 1 water data processor with respect to the previous MEGS-7.

3. The atmospherically corrected $L_{\mathrm{WN}}$ (or the equivalent $R_{\mathrm{rS}}$ ) resulting from the case- 2 water data processing should be added to the MERIS standard data products in view of an assessment of their relevance for CDRs.

Finally, the overall exercise once more reinforces the fundamental need for globally distributed and highly accurate in situ measurements to address uncertainties and biases affecting satellite ocean color data products. Additionally, the work strengthens the complementarity of continuous in situ data (e.g. AERONET-OC $L_{\mathrm{WN}}$ ) collected with autonomous systems and of occasional ship-borne measurements of derived ocean color products (e.g. Chla, $a_{\mathrm{dg}}$ ), both essential for a comprehensive validation strategy of data products from forthcoming ocean color sensors (e.g. Ocean and Land Colour Instrument).

Acknowledgements. The authors wish to thank ESA for supporting the present study through contract 21653/08/I-OL. Acknowledgments are due to NASA OBPG for granting access to MODIS and SeaWiFS data, and to the NASA AERONET team for the commitment to sustain AERONET-OC. The work benefitted support from the European Union Seventh Framework Programme under grant agreement no. 228344 (EUROFLEETS), from the European Metrology Programme through the European Metrology for Earth Observation and Climate Joint Research Project, and from the NATO Science for Peace and Security Programme project no. 982678 .

Edited by: O. Zielinski

\section{References}

Ahmad, Z., Franz, B. A., McClain, C. R., Kwiatkowska, E. J., Werdell,J., Shettle, E. P., and Holben, B. N.: New aerosol models for the retrieval of aerosol optical thickness and normalized water-leaving radiances from the SeaWiFS and MODIS sensors over coastal regions and open oceans, Appl. Opt., 49, 55455560, 2010.

Antoine, D. and Morel, A.: A multiple scattering algorithm for atmospheric correction of remotely sensed ocean color (MERIS instrument): Principle and implementation for atmospheres carrying various aerosols including absorbing ones, Int. J. Remote Sens., 20, 1875-1916, 1999.
Antoine, D., d'Ortenzio, F., Hooker, S. B., Bécu, G., Gentili, B., Tailliez, D., and Scott, A. J.: Assessment of uncertainty in the ocean reflectance determined by three satellite ocean color sensors (MERIS, SeaWiFS and MODIS-A) at an offshore site in the Mediterranean Sea (BOUSSOLE project), J. Geophys. Res., 113, C07013, doi:10.1029/2007JC004472, 2008.

Antoine, D., Bourg, L., Brockmann C., Doerffer, R., Fischer, J., Moore, J., Santer, R., and Zagolski, F.: Reference Model for MERIS Level 2 Processing - Third MERIS reprocessing: Ocean Branch, Report n. PO-TN-MEL-GS-0026-5 Rev. 2, available at: http://envisat.esa.int/instruments/meris/rfm/, 106 pp., 2012.

Attila, J., Koponen, S., Kallio, K., Lindfors, A., Kaitala, S., and Ylöstalo, P.: MERIS Case II water processor comparison on coastal sites of the northern Baltic Sea, Remote Sens. Environ., 128, 138-149, 2013.

Bailey, S. W., Franz, B. A., and Werdell, P. J.: Estimation of nearinfrared water-leaving reflectance for satellite ocean color data processing, Opt. Express, 18, 7521-7527, 2010.

Berthon, J.-F. and Zibordi, G.: Bio-optical relationships for the northern Adriatic Sea, Int. J. Remote Sens., 25, 1527-1532, 2004.

Berthon, J.-F., Zibordi, G., Doyle, J.P., Grossi, S., van der Linde, D., and Targa, C.: Coastal Atmosphere and Sea Time Series (CoASTS), Part 2: Data analysis. NASA Tech. Memo. TM-2002206892, v. 20, edited by: Hooker, S. B. and Firestone, E. R., NASA Goddard Space Flight Center, Greenbelt, Maryland, 25 pp., 2002.

Bourg, L. and Members of the MERIS Quality Working Group: MERIS 3rd data Reprocessing: Software and ADF updates, Report no. A879.NT.008.ACRI-ST, 21091/07/I-OL, available at: http://earth.eo.esa.int/pcs/envisat/meris/documentation/ meris_3rd_reproc/, 2011.

Brando, V. E. and Dekker, A. G.: Satellite hyperspectral remote sensing for estimating estuarine and coastal water quality, IEEE Trans. Geosci. Rem. Sens., 41, 1378-1387, 2003.

Canuti, E. and Berthon, J. -F.: The JRC Method, volume 2010215857 of Technical Memorandum, in: The Fourth SeaWiFS Analysis Round-Robin Experiment (SeaHARRE-4), edited by: Hooker, S. B., National Aeronautics and Space Administration, Greenbelt (MD), 52-55, 2010.

D'Alimonte, D., Zibordi, G., and Berthon, J.-F.: Statistical classification of seawater bio-optical types, IEEE Trans. Geosci. Rem. Sens., 45, 2644-2651, 2007.

D'Alimonte, D., Zibordi, G., Berthon, J.-F., Canuti, E., and Kajiyama, T.: Performance and applicability of bio-optical algorithms in different European seas, Remote Sens. Environ., 124, 402-412, 2012.

Eck, T. F., Holben, B. N., Reid, J. S., Dubovik, O., Smirnov, A., O'Neill, N. T., Slutsker, I., and Kinne, S.: The wavelength dependence of the optical depth of biomass burning, urban and desert dust aerosols, J. Geophys. Res., 104, 31333-31350, 1999.

Fu, G., Baith, K., and McClain, C.: The SeaWiFS Data Analysis System. Proceedings of the 4th Pacific Ocean Remote Sensing Conference, Quigdao, China, July 1998, 73-79, 1999.

Gordon, H. R. and Wang, M.: Retrieval of water-leaving radiance and aerosol optical thickness over the oceans with SeaWiFS: a preliminary algorithm, Appl. Optics, 33, 443-452, 1994.

Hays, G. C., Richardson, A. J., and Robinson, C.: Climate change and marine plankton, TRENDS Ecol. Evolut., 20, 337-344, 
2005.

Hoegh-Guldberg, O. and Bruno, J. F.: The Impact of Climate Change on the World's Marine Ecosystems, Science, 328, 1523$1528,2010$.

Holben, B. N., Eck, T. F., Slutsker, I., Tanré, D., Buis, J. P., Setzer, A., Vermote, E., Reagan, J. A., Kaufman, Y. J., Nakajima, T., Lavenu, F., Jankowiak, I., and Smirnov, A.: AERONET - A federated instrument network and data archive for aerosol characterization, Remote Sens. Environ., 66, 1-16, 1998.

Hu, C., Chen, Z., Clayton, T. D., Swarzenski, P., Brock, J. C., and Muller-Karger, F. E.: Assessment of estuarine water-quality indicators using MODIS medium-resolution bands: Initial results from Tampa Bay, FL, Remote Sens. Environ., 93, 423-441, 2004.

Kajiyama, T., D’Alimonte, D., and Zibordi G.: Match-up Analysis of MERIS Radiometric Data in the Northern Adriatic Sea, Geosci. Remote Sens. Lett., doi:10.1109/LGRS.2013.2244844, in press, 2013.

Louet, J.: The Envisat mission and system, ESA Bulletin, 106, 1125, 2001.

McClain, C. R. A Decade of Satellite Ocean Color Observations, Ann. Rev. Mar. Sci., 1, 19-42, 2009.

Mélin, F., Zibordi, G., and Berthon, J.-F.: Assessment of apparent and inherent optical properties derived from SeaWiFS with field data, Remote Sens. Environ., 97, 540-553, 2005.

Mélin, F., Zibordi, G., and Berthon, J.-F.: Assessment of satellite ocean color products at a coastal site, Remote Sens. Environ., 110, 192-205, 2007.

Mélin, F., Zibordi, G., Berthon, J.-F., Bailey, S., Franz, B., Voss, K.J., Flora, S., and Grant, M.: Assessment of MERIS reflectance data as processed by SeaDAS over the European Seas, Optics Express, 19, 25657-25671, 2011.

Morel, A., Antoine, D., and Gentili, B.: Bidirectional reflectance of oceanic waters: accounting for Raman emission and varying particle scattering phase function, Appl. Optics, 41, 6289-6306, 2002.

Morel, A., Huot, Y., Gentili, B., Werdell, P. J., Hooker, S. B., and Franz, B. A.: Examining the consistency of products derived from various ocean color sensors in open ocean (Case 1) waters in the perspective of a multisensory approach, Remote Sens. Environ., 111, 69-88, 2007.

Moore, G. F., Aiken, J., and Lavender, S. J.: The atmospheric correction of water colour and the quantitative retrieval of suspended particulate matter in Case II waters: Application to MERIS, Int. J. Rem. Sens., 20, 1713-1733, 1999.

Müller, D., Krasemann, H., Brewin, R. J. W., Brockmann, K., Deschamps, P. Y., Doerffer, R., Fomferra, N., Franz, B. A., Grant, M. G., Groom, S. B., Melin, F., Platt, T., Regner, P., Sathyendranath, S., Steinmetz, F., and Swinton, J.: The Ocean Colour Climate Change Initiative: I. A Methodology for assessing Atmospheric Correction Processors based on in-situ measurements, Remote Sens. Environ., accepted, 2013.

Ohring, G., Wielicki, B., Spencer, R., Emery, B., and Datla, R.: Satellite instrument calibration for measuring global climate change, Bull. Am. Meteorol. Soc., 86, 1303-1313, 2005.

Thuillier, G., Hersé, M., Labs, D., Foujols, T., Peetermans, W., Gillotay, D., Simon, P. C., and Mandel, H.: The solar spectral irradiance from 200 to $2400 \mathrm{~nm}$ as measured by the SOLSPEC spectrometer from the Atlas and Eureca missions, Solar Physics, 214, 1-22, 2003.
UNFCCC: Systematic Observation Rrequirements for SatelliteBased Data Products for Climate, Supplemental details to the satellite-based component of the "Implementation Plan for the Global Observing System for Climate in Support of the UNFCCC (2010 Update)", available at: http://www.wmo.int/pages/ prog/gcos/, 2011.

Wang, M., Knobelspiesse, K. D., and McClain, C. R.: Study of the Sea-viewing Wide Field-of-View Sensor (SeaWiFS) aerosol optical property data over ocean in combination with the ocean color products, J. Geophys. Res., 110, D10S06, doi:10.1029/ 2004JD004950, 2005.

Zibordi, G.: Comment on "Long Island Sound Coastal Observatory: assessment of above-water radiometric measurement uncertainties using collocated multi and hyperspectral systems", Appl. Optics, 51, 3888-3892, 2012.

Zibordi, G. and Berthon, J. F.: In situ relationships between the Qfactor and seawater optical properties in coastal regions, Limnol. Oceanogr., 46, 1130-1140, 2001.

Zibordi, G. and Voss, K. J.: Field Radiometricand Ocean Color Remote Sensing, in: Oceanography from Space, revisited, edited by: Barale, V., Gower, J. F. R., and Alberotanza, L., Springer, Dordrecht, 365-398, 2010.

Zibordi, G., Berthon, J.-F., Doyle, J. P., Grossi, S., van der Linde, D., Targa, C., and Alberotanza, L.: Coastal Atmosphere and Sea Time Series (CoASTS), Part 1: A long-term measurement program (2002), NASA Tech. Memo. 2002-206892, v. 19, edited by: Hooker, S. B. and Firestone, E. R., NASA Goddard Space Flight Center, Greenbelt, MD, 29 pp., 2002.

Zibordi, G., Mélin, F., and Berthon, J.-F.: Comparison of SeaWiFS, MODIS and MERIS radiometric products at a coastal site, Geophys. Res. Lett., 33, L06617, doi:10.1029/2006GL025778, 2006.

Zibordi, G., Holben, B., Slutsker, I., Giles, D., D’Alimonte, D., Mélin, F., Berthon, J.-F., Vandemark, D., Feng, H., Schuster, G., Fabbri, B. E., Kaitala, S., and Seppälä, J.: AERONET-OC: a network for the validation of Ocean Color primary radiometric products, J. Atmos. Oc. Technol., 26, 1634-1651, 2009 a.

Zibordi, G., Berthon, J.-F., Mélin, F., D’Alimonte, D., and Kaitala, S.: Validation of satellite ocean color primary products at optically complex coastal sites: Northern Adriatic Sea, Northern Baltic Proper and Gulf of Finland, Remote Sens. Environ., 113, 2574-2591, 2009b.

Zibordi, G., Holben, B., Mélin, F., D’Alimonte, D., Berthon, J.-F., Slutsker, I., and Giles, D.: AERONET-OC: an overview, Cnd. J. Rem. Sens., 36, 488-497, 2010.

Zibordi, G., Berthon, J.-F., Mélin, F., and D'Alimonte, D.: Crosssite consistent in situ measurements for satellite ocean color applications: The BiOMaP radiometric dataset, Remote Sens. Environ., 115, 2104-2115, 2011.

Zibordi, G., Ruddick, K., Ansko, I., Moore, G., Kratzer, S., Icely, J., and Reinart, A.: In situ determination of the remote sensing reflectance: an inter-comparison, Ocean Sci., 8, 567-586, doi:10.5194/os-8-567-2012, 2012a.

Zibordi, G., Mélin, F., and Berthon, J.-F.: Intra-annual variations of biases in remote sensing primary ocean color products at a coastal site, Remote Sens. Environ. 124, 627-636, 2012 b. 